\title{
Ecosystem Services Flow and Its Coupling Evaluate of Supply and Demand - A Case Study of Yihe River Basin
}

\author{
H. M. Liu ${ }^{1,2,3 *}$ S. Y. Ding ${ }^{2,3}$, and J. Y. Ren ${ }^{2,3,4}$ \\ ${ }^{1}$ Civil and Economic Law College, Henan University of Economics and law, Zhengzhou 450000, China \\ ${ }^{2}$ Key Laboratory of Geospatial Technology for the Middle and Lower Yellow River Regions, Henan University, Ministry of Education, \\ Kaifeng 475004, China \\ ${ }^{3}$ College of Geography and Environmental Science, Henan University, Kaifeng 475004, China \\ ${ }^{4}$ State Key Joint Laboratory of Environmental Simulation and Pollution Control, China-Canada Center for Energy, Environment and \\ Ecology Research, UR-BNU, School of Environment, Beijing Normal University, Beijing 100875, China
}

Received 26 July 2021; revised 14 August 2021; accepted 29 August 2021; published online 06 November 2021

\begin{abstract}
Ecosystem services flows (ESF) is an important contributor to the delivery, transformation, utilization, and maintenance of ecosystem services (ES). It provides linkages between the provision of ecosystem services and human demands. The landscape area and dynamic changes in Yihe River Basin were explored through ArcGIS, and the regional ecosystem services value evaluation matrix were also developed through the expert experience, based on which supply rate (SR) and supply-demand ratio (SDR) were constructed. The ecological balance and sustainable development of the Yihe River Basin were discussed based on the potential supply of ecosystem services, and variations in actual human demand at different temporal-spatial scales. The state of ecological balance and sustainable development was also identified based on the spatially explicit model. The result shows: (1) the speed of single land use change dynamics of construction land in the Yihe River Basin was the fastest in the past 30 years. The largest variation of comprehensive land use change dynamics was occurred during $1987 \sim 1995$, while the smallest was in $1995 \sim 2005$; (2) the minimum and maximum values of the overall ecosystem services SR were 0.500 and 0.916 over the Yihe River Basin in the past 30 years, respectively. There is a noticeable spatial differentiation in the balance of supply and demand in the river basin, the upper reaches were in an ecological surplus area, while the middle and lower reaches were in an ecological deficit; (3) the actual ES delivered by the flows to humans account for a large proportion of potential ES in the Yihe River Basin. However, the services flow and the balance of the ecosystem in the Yihe River Basin were decreased during $1987 \sim 2015$. Although the ecological deficit area in the basin was increased significantly, the Yihe River Basin was still in a sustainable state in 2015 . The climate regulation service produced by the forest was the most essential contributor to the sustainable development of the Yihe River Basin, including the service of local climate regulation and air quality regulation. The results were expected to provide valuable information for ecosystem management and formulate desired ecological compensation policies.
\end{abstract}

Keywords: ecosystem services flow, ecosystem services demand, supply and demand coupling

\section{Introduction}

Ecosystem services (ES) are the environmental conditions of ecosystem formation and maintenance of human survival and development, as well as the products and services that humans obtained from the ecosystem directly or indirectly (Daily, 1997; Robert et al.,1997; Ma et al., 2017). ES were divided into four categories, including provision, regulation, culture, and support services (Millennium Ecosystem Assessment, 2005). Previously, a number of scholars have explored the hot topics in ES. For instance, the mechanisms of ES generation, trade-off coordination, driving mechanisms, supply-demand balance, and the quantitative research on ES were explored in the past few

${ }^{*}$ Corresponding author. Tel.: +86-155-1558-7845.

E-mail address: liuhuimingirl@126.com (H. M. Liu).

ISSN: 2663-6859 print/2663-6867 online

(C) 2021 ISEIS All rights reserved. doi:10.3808/jeil.202100072 years (Liu et al., 2019a; Deng and Liao, 2020; Li et al., 2021). The evaluation of the ES value can identify the damage degree of the ecosystem and ES, as well as the importance of ES to human wellbeing (Yin et al., 2021). The evaluation can also provide a scientific basis for the formulation of ecological management and related protection policies (Millennium Ecosystem Assessment, 2005). However, ES has mobility and regional differences due to the spatial heterogeneity between the production area and the demand area of ES. These characteristics hinder the accurate assessment of ES. Repeated calculations will also affect the validity of the evaluation of these results. Ecosystem services flows (ESF) are the spatial and temporal processes in a basin or landscape ecosystem in which ES generated in the supply area are delivered to human demand areas with a carrier, driven by natural factors or human factors and along certain directions and paths (Liu et al., 2017a). ESF displays the dynamic process of a certain ES with mobility and transitivity in different spatial-temporal scales. This could dynamical- 
ly couple the supply and demand of ES (Wang and Zhou, 2019). The intermediate process from the zone to the beneficiary zone is an indispensable link between the natural ecosystem and the socio-economic system (Liu et al., 2016).

The generation of ESF is a very complex process, which integrates the biophysical process, human needs, regulation, and management (Gary et al., 2016). ESF can connect ecosystems and socio-economic systems. The ESF flows through three areas, including the supply area, the connection area, and the demand area. Therefore, the supply and demand of ESF are important. ES supply refers to the ecosystem products and services that are provided to human beings through the ecological integrity itself in a certain spatial-temporal scale (Xie et al., 2008). The supply of ES can be divided into potential and actual supplies. The ability of the ecosystem that provides services based on biophysical properties, social conditions, and ecological functions is the potential supply of ES (Francesc et al., 2016), which is equal to the stock of the natural capital. While the ES or products that humans obtain from the ecosystem is the actual supply of ES, which equals the ESF (Serna-Chavez et al., 2014). ES demand is the use and consumption of products and services produced by the ecosystem. The relationship between ES supply potential, flow, and demand can be analyzed in pairs by supply potential-flow, flow-demand (Francesc et al., 2016). The potential supply arises from natural ecosystems and represents the inventory of ES. The assessment process will be subject to spatial-temporal scales. The ESF is the actual acquisition of ES by humans. The relationship between potential supply, ESF, and demand can be reflected into two categories, there are overused service (i.e., supply potential < ESF) and moderately used service (i.e., supply potential $\geq E S F$ ). Whether potential supply and flows match or not can indicate the state of ES (i.e., ES is sustainably used or unsustainably acquired). Demand originates from the socio-economic system, which is the preference or expectation for service that from the human. The relationship between ESF and demand can also be identified in two ways, that is satisfied (ESF $\geq$ demand) and unsatisfied (ESF < demand). Whether the ESF matches the demand reflects the degree of the social demand is being met (Liu et al., 2017a).

At present, fewer scholars have quantified the ESF. The exploration of ESF is at the stage of qualitative description. For example, rangeland ES were used as the object of study to evaluate the supply of nature and the demand of humans (Sala et al., 2017); flood regulation ES in the city of Etropole, Bulgaria, were used as a study to map supply and demand (Stoyan and Benjamin, 2012); the ESF at the urban scale was reviewed by Zhang and Lu (2020). Liu et al. (2017b) explored the dilemma of evaluating ESF; Mo et al. (2021) evaluated the degradation of atmospheric PM2.5 by wetland based on the theory of ESF and quantified the urban ESF based on entropy theory.

This research attempts to evaluate the ESF through constructing an ESF matrix in areas where data is lacking. However, the basin usually does not overlap with its administrative and physical boundaries completely. This makes it difficult to obtain valid data when assessing ESF. The Yihe River Basin is located in the mountainous region of western Henan province, which is one of the most important sub-basins of the Yellow River
Basin. The basin has diverse landscape types and rich biodiversity, and the maintenance of its ecological environment is crucial to the ecological security of the middle and lower reaches of the Yellow River. However, frequent human activities have led to widespread ecological damage and environmental pollution in recent years (Liu et al., 2018), a comprehensive assessment of the supply, flow and demand of ES is needed for scientific protection of the ecological environment in the basin. The basin is made up of four parts, Luanchuan, Songxian, Yichuan, and Yanshui City (Ren et al., 2017). They are not within the administrative boundaries of these cities completely, and it would be difficulty in obtaining data if other methods are used to assess ESF. Therefore, it is feasible to use the ecosystem service matrix method to conduct a study of ESF and their supplydemand coupling in the Yihe River Basin.

The objective of this study is to explore the ESF of the Yihe River Basin through the ES matrix. In detail, (1) constructing an ESF assessment framework through expert experience; (2) discussing the changes in ESF, the potential supply of ES, and human demand in the dimensions of time and space in the Yihe River Basin; (3) exploring whether the Yihe River Basin is in a state of sustainable development or not and providing support for the related ecological management. ESF and associated research are not only conducive to the accurate assessment of ES values but also are of great significance for exploring the relationship between the temporal-spatial dynamics of ES supply and variations in human welfare. The study of ESF and their coupling is an important management optimization measure that plays a positive guiding role, which can also provide help for coordinating the balance of social, economic, and ecological benefits, and sustainable development of the region.

\section{Overview of the Study Area}

Yihe River Basin $\left(33^{\circ} 39^{\prime} \sim 34^{\circ} 17^{\prime} \mathrm{N}, 111^{\circ} 20^{\prime} \sim 112^{\circ} 11^{\prime} \mathrm{E}\right)$ is located in the middle and lower reaches of the Yellow River in the south and west of Henan Province (Figure 1). The basin area is about $5,846 \mathrm{~km}^{2}$. The terrain is high in the southwest and low in the northeast. The altitude is between 110 and 2,200 $\mathrm{m}$, its natural geographical elements have an obvious transition from upstream to downstream, forming a unique "mountainhill-plain" landscape ecosystem continuum (Liu et al., 2019b). The Yihe River Basin is located in a warm temperate continental monsoon climate area, with high temperatures and rainfall in summer, and colder and drier winters. The elevation of different areas in the basin is very different, and the terrain is complex and changeable. The major soil types in the Yihe River Basin are diverse. There are differences in rainfall in the Yihe River Basin. The runoff mountain area is greater than the hilly area and the plain area, the southern bank of the Yihe River is larger than the north bank, and the upper reaches of the river basin are greater than the middle and lower reaches. The economic development of different administrative regions in the lower and upper reaches of the Yihe River Basin is significantly different. The overall economic level in the upper and lower reaches is relatively low, while the economic development level downstream is relatively high. The forest coverage rate in the 
Yihe River Basin, especially in the upper reaches, is high. Although the development of the resource-based economy has increased the GDP of the area and accelerated the economic and social development of the area, the extensive management model accompanying mineral development has given locally. In addition, the middle and lower reaches of the region bring serious environmental pollution and ecological damage.

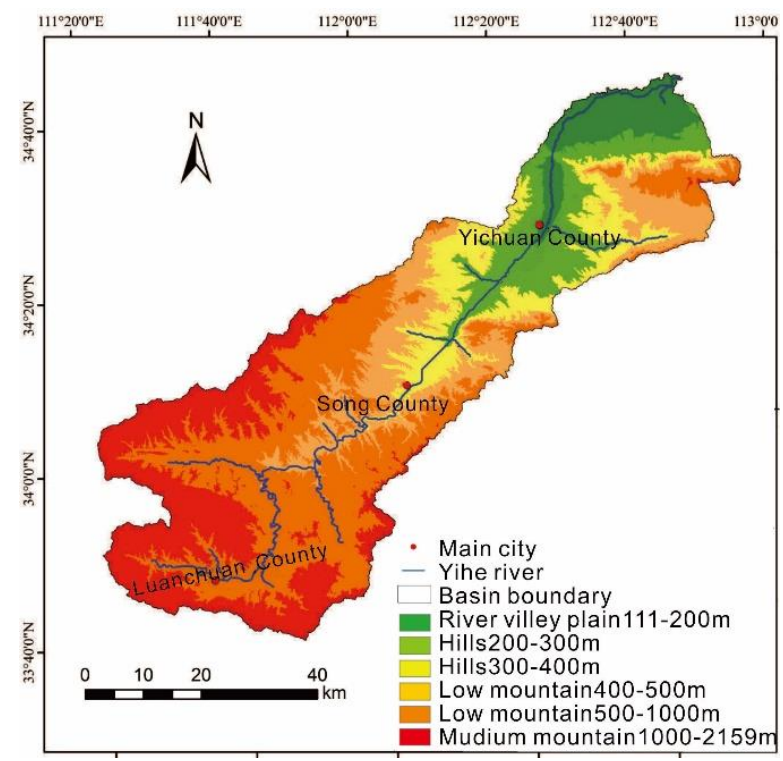

Figure 1. Location of the study area.

\section{Methodology}

\subsection{Acquisition and Processing of Land Use/Cover Change Data}

The resolution of the Land Use/Cover Change (LUCC) data in Yihe River Basin in 1987, 1995 and 2005 comes from the National Geographic Resource Science Sub Center, National Earth System Science Data Center, National Science and Technology Infrastructure of China (http://gre.geodata.cn). The original LUCC data of 2015 was obtained based on the Landsat TM remote sensing image data. The remote sensing then was imported into ENVI 5.1 to synthesize the initial multispectral image data. After cropping, geometric calibrating, and configuration, the interpretation of the remote sensing in the field was performed. According to the obtained land use/cover data from 1987 to 2005, a landscape classification system for the 2015 study area was established, and the landscape types were divided into seven categories, including forest land, grassland, arable land, river channels, reservoirs and ponds, building land, and unused land. Figure 2 shows the land cover map of the Yihe River Basin in 1987, 1995, 2005 and 2015.

\subsection{Dynamic Variations of Landscape Area}

Statistical analysis of the area of landscape types in the study area can reveal the changes in the size of land-use in different time zones, but the description of the change process and speed of the landscape ecosystem in time and space requires a functional relationship, that is the degree of land-use change. It can not only compare the spatial differences of landscape ecosystem changes but also predict the trends and rates of land landscape changes in the next few decades, which will have a positive effect on the study of ecosystem balance. The degree of land-use change includes the single land-use dynamic degree describing the change of the quantity of a certain land type within a certain time range of the study area (Zhu and Li, 2003) and the comprehensive land-use dynamic degree of the comprehensive land-use change rate in the study area (Lang et al., 2011). The expression formula is as follows:

$K=\frac{V_{b}-V_{a}}{V_{a}} \times \frac{1}{T_{2}-T_{1}} \times 100 \%$

where $K$ represents the dynamic change degree of a certain land-use type in a certain period. The value of $K$ is positive or negative, and greater than 0 indicates that the area and rate of land types in the study area are increasing. Negative values indicate land types in the study area. Area and rate are decreasing; $V_{b}$ is the area of a certain land-use type at the end of the study period $\left(\mathrm{hm}^{2}\right) ; V_{a}$ is the area of a certain land-use type at the beginning of the study period $\left(\mathrm{hm}^{2}\right) ; T_{2}-T_{1}$ is the study period (a):

$L C=\frac{\sum_{i=1}^{n} \Delta L U_{i-j}}{2 \sum_{i=1}^{n} L U_{i}} \times \frac{1}{T_{2}-T_{1}} \times 100 \%$

where $L C$ is the dynamic degree of the comprehensive land-use type. It represents the interannual change rate of the overall landscape in the study area in units of years. There is no difference between the positive and negative values. $L U_{i}$ is the type $i$ land at the initial point of the study period. Area of utilization type $\left(\mathrm{hm}^{2}\right) ; \Delta L U_{i-j}$ is the absolute value $\left(\mathrm{hm}^{2}\right)$ of type $i$ landuse type conversion to other land-use types from the beginning to the end of the study; $T_{2}-T_{1}$ is the study period $(a)$.

\subsection{Construction of the Ecosystem Service Matrix of Yihe River Basin}

Ecosystems rely on land cover types to produce different types of ES, then passed to the demand area through ESF. Social, economic, and cultural factors will cause changes in human demand, and indirectly change the types of land cover through macro-control and market mechanisms, which in turn would affect the ESF, supply and demand. Therefore, the supplydemand location of ES can be identified based on the land cover type. Based on the type of land cover in the region, the spatial locations of the supply and demand areas for various adjustments, supplies, and cultural services have been summarized (Table 1). The location of the ecosystem service connection area can be judged according to the type of ecosystem service flow carriers (Benjamin et al., 2014). The connecting area of ES with air as the carrier is the wind direction, the connection area of ES with water as the carrier is a river. 
Table 1. The Location of ES Supply and Demand Area

\begin{tabular}{|c|c|c|c|}
\hline ES types & & $\begin{array}{l}\text { Supply area } \\
\text { location }\end{array}$ & $\begin{array}{l}\text { Demand area } \\
\text { location }\end{array}$ \\
\hline \multirow[t]{5}{*}{$\begin{array}{l}\text { Regulate } \\
\text { services }\end{array}$} & $\begin{array}{l}\text { Local } \\
\text { climate } \\
\text { regulation }\end{array}$ & $\begin{array}{l}\text { Forest, wetland, lake, } \\
\text { ocean, green space }\end{array}$ & $\begin{array}{l}\text { Residential and } \\
\text { leisure areas }\end{array}$ \\
\hline & $\begin{array}{l}\text { Air quality } \\
\text { regulation }\end{array}$ & $\begin{array}{l}\text { Woods, hedges, green } \\
\text { spaces, pastures }\end{array}$ & $\begin{array}{l}\text { Residential and } \\
\text { leisure areas }\end{array}$ \\
\hline & $\begin{array}{l}\text { Water } \\
\text { purification }\end{array}$ & $\begin{array}{l}\text { Water body, riparian } \\
\text { zone, soil, forest, } \\
\text { wetland, grassland, } \\
\text { intertidal zone }\end{array}$ & $\begin{array}{l}\text { Residential or } \\
\text { leisure area, } \\
\text { agriculture, } \\
\text { industry }\end{array}$ \\
\hline & $\begin{array}{l}\text { Erosion } \\
\text { regulation }\end{array}$ & $\begin{array}{l}\text { Woodland, } \\
\text { agriculture, forestry } \\
\text { and animal husbandry } \\
\text { transition zone, } \\
\text { pasture, grassland }\end{array}$ & $\begin{array}{l}\text { Residential area, } \\
\text { agriculture, } \\
\text { infrastructure }\end{array}$ \\
\hline & $\begin{array}{l}\text { Pollination } \\
\text { regulation }\end{array}$ & $\begin{array}{l}\text { Garden, orchard, } \\
\text { forest, wetland, } \\
\text { agricultural area }\end{array}$ & $\begin{array}{l}\text { Agricultural area, } \\
\text { garden, plant area, } \\
\text { fruit plantation }\end{array}$ \\
\hline \multirow[t]{3}{*}{$\begin{array}{l}\text { Supply } \\
\text { services }\end{array}$} & Food supply & $\begin{array}{l}\text { Farmland, plant area, } \\
\text { farmer, orchard }\end{array}$ & $\begin{array}{l}\text { Farm, food } \\
\text { factory, } \\
\text { community, } \\
\text { family }\end{array}$ \\
\hline & $\begin{array}{l}\text { Wood } \\
\text { supply }\end{array}$ & $\begin{array}{l}\text { Forest, afforestation } \\
\text { area, orchard, } \\
\text { agriculture and } \\
\text { forestry }\end{array}$ & $\begin{array}{l}\text { Home, wood } \\
\text { industry, } \\
\text { construction area, } \\
\text { community }\end{array}$ \\
\hline & $\begin{array}{l}\text { Fresh water } \\
\text { supply }\end{array}$ & $\begin{array}{l}\text { Reservoirs, rivers, } \\
\text { glaciers, groundwater }\end{array}$ & $\begin{array}{l}\text { Water company, } \\
\text { agriculture, } \\
\text { industry, } \\
\text { community, } \\
\text { household }\end{array}$ \\
\hline \multirow[t]{2}{*}{$\begin{array}{l}\text { Cultural } \\
\text { services }\end{array}$} & $\begin{array}{l}\text { Leisure and } \\
\text { tourism }\end{array}$ & $\begin{array}{l}\text { Forests, water bodies, } \\
\text { mountain peaks, urban } \\
\text { green spaces, gardens, } \\
\text { leisure facilities }\end{array}$ & $\begin{array}{l}\text { Tourism } \\
\text { infrastructure, } \\
\text { visitors, } \\
\text { communities, } \\
\text { residential areas }\end{array}$ \\
\hline & $\begin{array}{l}\text { Landscape } \\
\text { aesthetics }\end{array}$ & $\begin{array}{l}\text { Landscape, seascape, } \\
\text { body of water, river, } \\
\text { forest }\end{array}$ & $\begin{array}{l}\text { Tourism } \\
\text { infrastructure, } \\
\text { residential areas, } \\
\text { industries, visitors }\end{array}$ \\
\hline
\end{tabular}

In recent years, scholars have proposed to construct an ecosystem service matrix to express the ability of different land types to generate ES supply, flow, and demand (Benjamin et al., 2012). The ecosystem service matrix can reflect 44 types of land-use in the region to 29 different ES provided by it. Based on expert knowledge, the ES potential supply capacity, flow, and demand of each type of land are divided into six levels, which are represented by numbers from 0 to $5(0 \sim 5$ means that there is no relevant ES supply potential, flow, or human demand, followed by general, medium, strong, and very strong related ES supply potential, flow, or human demand). The ecosystem service matrix includes ES potential supply matrix, human demand matrix, and ESF matrix; through the ES matrix, a diversified evaluation index system can be constructed, which is an innovative method for quantifying $\operatorname{ESF}(\mathrm{Li}, 2014)$. At present, the ES matrix has been used in the northern part of Finland, the North Sea in Germany, and the Baiyangdian Basin in China (Bai et al., 2017).
Through the interpretation of remote sensing images, the Yihe River Basin was divided into seven types of land cover. Choose experts who have in-depth research on landscape ecology, understand the physical geography and social economy of the Yihe River Basin and are familiar with ES. Based on the experience of experts, the assignment method was used to score the regulation services, supply services, and cultural services provided by different land cover types in the Yihe River Basin (Some scholars believed that the quantification of support services will cause double accounting for other types of services, so they were excluded). Based on the revision and discussion of previous studies, the Yihe River Basin supply potential matrix (Table 2), flow matrix (Table 3), and demand matrix (Table 4) were obtained.

\subsection{Construction of Supply-Demand Balance Indicators for ESF}

There is a close relationship between ES potential supply, ESF, and human demand. Using these three variables, the ES supply rate (SR) and supply-demand ratio (SDR) index can be constructed. These two indexes are conducive to the comparison of ES characteristics between and within different regions (Bai et al., 2017).

Supply rate $=\frac{\text { ES flow(Actual supply) }}{\text { Potential supply }}$

Supply - demand ratio

$=\frac{\text { ES flow }- \text { Human demand }}{\text { Potential supply } y_{\max }+\text { Human demand } \max / 2}\left\{\begin{array}{c}>0, \text { surplus } \\ =0, \text { balance } \\ <0, \text { deficit }\end{array}\right\}$

The SR is the capacity of a regional ecosystem to provide actual supply, that is, the flow of ES provided. The larger the ratio of the $S R$, the more the potential supply services of the ecosystem are converted into the actual supply services, or the greater the flow of ESF provided by the ecosystem. The SDR characterizes the balance between the supply of ES and human demand in the region. When the SDR is positive, it means that the supply of regional ES is greater than demand, and the region is in an ecological surplus. When the SDR is equal to zero, it means that the supply of regional ES equals the demand, and the region is in an ecological balance. When the SDR is negative, it means that the supply of regional ES is less than the demand, and the region is in an ecological deficit.

\section{Results}

\subsection{Landscape Area and Dynamic Changes in the Yihe River Basin}

4.1.1. Changes in the Area and Structure of the River Basin Landscape

The landscape area of the Yihe River Basin in 1987, 1995, 2005 and 2015 was calculated and shown in Figure 3. The dom- 

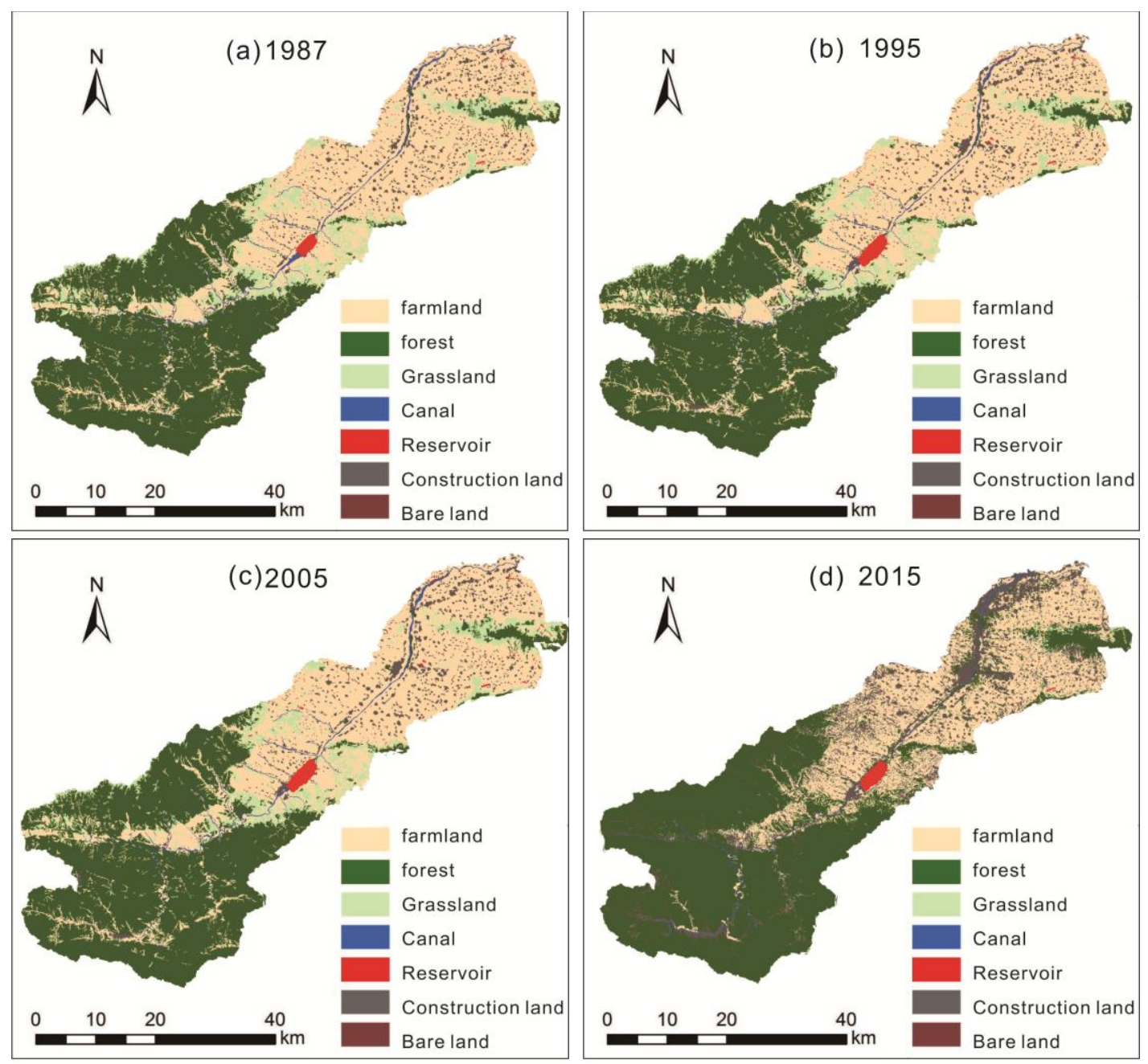

Figure 2. The variations of LUCC over the Yihe River Basin in 1987, 1995, 2005 and 2015.

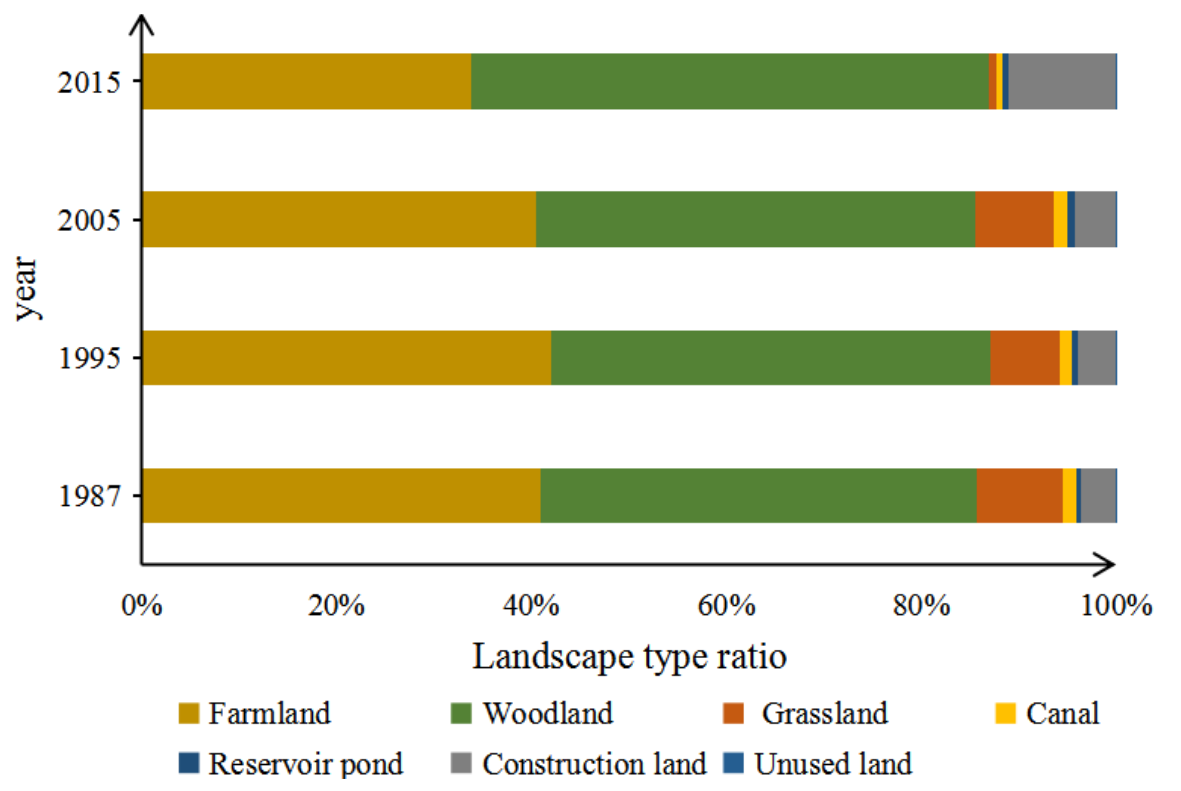

Figure 3. LUCC structural tures of Yihe River Basin from 1987 to 2015. 
Table 2. Ecosystem Service Potential Supply Matrix in Yihe River Basin

\begin{tabular}{|c|c|c|c|c|c|c|c|c|c|c|c|c|c|c|c|c|c|c|}
\hline \multirow{2}{*}{$\begin{array}{l}\text { Service } \\
\text { Code** }\end{array}$} & \multicolumn{7}{|c|}{ Regulation services } & \multicolumn{6}{|c|}{ Provision servicess } & \multicolumn{5}{|c|}{ Cultural services } \\
\hline & $\mathrm{a}$ & $\mathrm{b}$ & $\mathrm{c}$ & $\mathrm{d}$ & $\mathrm{e}$ & f & g & $\mathrm{h}$ & $\mathrm{i}$ & $\mathrm{g}$ & $\mathrm{k}$ & 1 & $\mathrm{~m}$ & $\mathrm{n}$ & o & $\mathrm{p}$ & $\mathrm{q}$ & $\mathrm{r}$ \\
\hline Farmland & 2 & 1 & 2 & 0 & 0 & 1 & 1 & 5 & 5 & 0 & 0 & 0 & 0 & 1 & 1 & 2 & 3 & 0 \\
\hline Forest & 5 & 5 & 3 & 5 & 5 & 4 & 4 & 0 & 1 & 0 & 5 & 0 & 0 & 5 & 5 & 5 & 4 & 5 \\
\hline Grassland & 2 & 1 & 1 & 3 & 5 & 1 & 1 & 0 & 1 & 3 & 0 & 0 & 0 & 3 & 4 & 5 & 3 & 3 \\
\hline Chanel & 1 & 0 & 3 & 3 & 0 & 3 & 0 & 0 & 2 & 0 & 0 & 3 & 5 & 4 & 4 & 4 & 3 & 3 \\
\hline Reservoir & 2 & 0 & 5 & 2 & 0 & 3 & 0 & 0 & 1 & 0 & 0 & 4 & 5 & 5 & 4 & 4 & 3 & 3 \\
\hline Construction land & 0 & 0 & 0 & 0 & 0 & 0 & 0 & 0 & 0 & 0 & 0 & 0 & 0 & 0 & 0 & 0 & 2 & 0 \\
\hline Unuse land & 0 & 0 & 0 & 1 & 2 & 1 & 0 & 0 & 0 & 0 & 0 & 0 & 0 & 2 & 3 & 2 & 2 & 1 \\
\hline
\end{tabular}

* Codes in Table 1 represent different ES, a (Local climate regulation), b (Air quality regulation), c (Water flow regulation), d (Water purification), e (Erosion regulation), f (Natural disaster protection), g (Pollination regulation), h (crop), i (Biomass energy), $\mathrm{j}$ (Biological product supply), k (wood), 1 (Aquatic products), $\mathrm{m}$ (freshwater), $\mathrm{n}$ (Leisure Travel), o (Landscape aesthetics), p (Knowledge System), q (Cultural heritage), and $\mathrm{r}$ (Natural heritage).

Table 3. Ecosystem Service Actual Supply Matrix (ESF Matrix) in Yihe River Basin

\begin{tabular}{|c|c|c|c|c|c|c|c|c|c|c|c|c|c|c|c|c|c|c|}
\hline \multirow{2}{*}{$\begin{array}{l}\text { Service } \\
\text { Code }\end{array}$} & \multicolumn{7}{|c|}{ Regulation services } & \multicolumn{6}{|c|}{ Provision services } & \multicolumn{5}{|c|}{ Cultural services } \\
\hline & $\mathrm{a}$ & $\mathrm{b}$ & $\mathrm{c}$ & $\mathrm{d}$ & $\mathrm{e}$ & $\mathrm{f}$ & $\mathrm{g}$ & $\mathrm{h}$ & $\mathrm{i}$ & $\mathrm{g}$ & $\mathrm{k}$ & 1 & $\mathrm{~m}$ & $\mathrm{n}$ & $\mathrm{o}$ & $\mathrm{p}$ & $\mathrm{q}$ & $\mathrm{r}$ \\
\hline Farmland & 2 & 1 & 2 & 0 & 0 & 1 & 3 & 4 & 4 & 0 & 0 & 0 & 0 & 1 & 1 & 1 & 1 & 4 \\
\hline Forest & 5 & 5 & 3 & 4 & 5 & 3 & 1 & 0 & 1 & 0 & 1 & 0 & 0 & 4 & 4 & 4 & 2 & 2 \\
\hline Grassland & 2 & 0 & 1 & 3 & 5 & 1 & 2 & 0 & 0 & 1 & 0 & 0 & 0 & 3 & 4 & 4 & 2 & 2 \\
\hline Chanel & 1 & 0 & 3 & 3 & 0 & 3 & 0 & 0 & 0 & 0 & 0 & 2 & 2 & 4 & 4 & 3 & 2 & 2 \\
\hline Reservoir & 2 & 0 & 3 & 2 & 0 & 3 & 0 & 0 & 0 & 0 & 0 & 2 & 2 & 5 & 4 & 3 & 2 & 2 \\
\hline Construction land & 0 & 0 & 0 & 0 & 0 & 0 & 0 & 0 & 0 & 0 & 0 & 0 & 0 & 0 & 0 & 0 & 1 & 0 \\
\hline Unuse land & 0 & 0 & 0 & 1 & 2 & 1 & 0 & 0 & 0 & 0 & 0 & 0 & 0 & 2 & 3 & 2 & 1 & 1 \\
\hline
\end{tabular}

Table 4. Ecosystem Service Demand Matrix in Yihe River Basin

\begin{tabular}{lllllllllllllllllll}
\hline Service & \multicolumn{4}{c}{ Regulation services } & \multicolumn{4}{c}{ Provision services } & \multicolumn{4}{c}{ Cultural services } \\
Code & $\mathrm{a}$ & $\mathrm{b}$ & $\mathrm{c}$ & $\mathrm{d}$ & $\mathrm{e}$ & $\mathrm{f}$ & $\mathrm{g}$ & $\mathrm{h}$ & $\mathrm{i}$ & $\mathrm{g}$ & $\mathrm{k}$ & $\mathrm{l}$ & $\mathrm{m}$ & $\mathrm{n}$ & $\mathrm{o}$ & $\mathrm{p}$ & $\mathrm{q}$ & $\mathrm{r}$ \\
\hline Farmland & 2 & 1 & 2 & 0 & 3 & 2 & 3 & 0 & 1 & & 0 & 0 & 0 & 0 & 0 & 1 & 1 & 0 \\
Forest & 0 & 0 & 0 & 0 & 0 & 0 & 0 & 0 & 0 & 0 & 0 & 0 & 0 & 0 & 0 & 0 & 0 & 0 \\
Grassland & 0 & 0 & 0 & 0 & 0 & 0 & 0 & 0 & 0 & 0 & 0 & 0 & 0 & 0 & 0 & 0 & 0 & 0 \\
Chanel & 0 & 0 & 0 & 0 & 0 & 0 & 0 & 0 & 0 & 0 & 0 & 0 & 0 & 0 & 0 & 0 & 0 & 0 \\
Reservoir & 0 & 0 & 0 & 0 & 0 & 0 & 0 & 0 & 0 & 0 & 0 & 0 & 0 & 0 & 0 & 0 & 0 & 0 \\
Construction land & 5 & 5 & 4 & 5 & 1 & 5 & 1 & 5 & 5 & 5 & 3 & 5 & 5 & 4 & 4 & 3 & 4 & 4 \\
Unuse land & 0 & 0 & 0 & 0 & 0 & 0 & 0 & 0 & 0 & 0 & 0 & 0 & 0 & 0 & 0 & 0 & 0 & 0 \\
\hline
\end{tabular}

Table 5. Landscape Type Dynamics and Comprehensive Dynamic Degree in Different Years of Yihe River Basin

\begin{tabular}{lllll}
\hline \multirow{2}{*}{ Landscape type } & \multicolumn{4}{l}{ Dynamics of landscape types in different years (\%) } \\
& $1987 \sim 1995$ & $1995 \sim 2005$ & $2005 \sim 2015$ & $1987 \sim 2015$ \\
\hline Arable land & 0.32 & -0.37 & -1.65 & -0.63 \\
Woodland & 0.07 & 0.02 & 1.78 & 0.67 \\
Grassland & -2.30 & 1.25 & -9.14 & -3.29 \\
Canal & -0.91 & 0.14 & -4.72 & -1.80 \\
Reservoir pit & 2.74 & 3.53 & -2.53 & 0.83 \\
Building land & 0.78 & 1.17 & 15.87 & 7.40 \\
Unused & 91.42 & -8.51 & -4.10 & -0.96 \\
Comprehensive dynamics & 2.09 & 0.16 & 1.49 & 0.57 \\
\hline
\end{tabular}

inant landscape type of the Yihe River Basin from 1987 to 2015 was woodland, followed by cultivated land. While the area of grassland, waters, building land, and unused land is small (Figure 3). By analyzing the proportion of each land-use type in the entire landscape, it can be seen that the landscape structure of the Yihe River Basin has changed between 1987 and 2015, but the overall dominant landscape type has not changed. The area of forest land accounted for about $45.0 \%$ of the total area from 1987 to 2005 . The area of forest land increased suddenly, accounting for about $53.2 \%$ of the total landscape area until 2015. The increase in forest area is mainly due to the fact that Luanchuan County, the upstream area of the Yihe River Basin, has 
become a South-North Water Transfer water source protection zone (Shi et al., 2019). To protect the ecological environment of the water source area from being destroyed, China has implemented ecological engineering projects such as returning farmland to forest and closing mountains for reforestation since 2002, and this measure has led to a continuous increase in the forest area of the water source protection (Gao et al., 2019). In 2005, China began to execute the "South-North Water Transfer Central Water Source Area Water Pollution Prevention and Soil and Water Conservation Plan", which has strengthened water pollution prevention and control, resulting in a significant improvement in the ecological environment of the water source protection zone (Liu et al., 2015). The area of arable land accounted for about $41.0 \sim 42.0 \%$ of the total landscape area from 1987 to 2005 , but it quickly decreased to $33.77 \%$ in 2015 , a larger decrease. The decrease in arable land area is associated with an increase in the area of building land, and the expansion of building land in the basin is partially occupying arable land. Except for forest land and cultivated land, the total landscape area occupied by other land-use types such as grassland, construction land, and river canals were small, less than $15 \%$ in total; the area of forest land and construction land gradually increased, while cultivated land and the area of grassland was gradually decreasing from 1987 to 2015 . The area of river canals and reservoirs and ponds showed an upward trend from 1987 to 2005; the area of both types of landscapes decreased in 2015. The proportion of unused land in the total landscape area was the smallest, but the area proportion increased relatively in 1995.

\subsubsection{Dynamic Changes of River Basin Landscape}

According to the area of different landscape types and their changes in the Yihe River Basin from 1987 to 2015, the landscape dynamics and comprehensive land-use dynamics in the Yihe River Basin were calculated based on the Formulas (1) and (2) during $1987 \sim 1995,1995 \sim 2005,2005 \sim 2015$, and $1987 \sim 2015$ (Table 5). As for single land-use change, the dynamic degree of building land reached $15.87 \%$ during 2005 2015 , which is much higher than other landscape types. The speed of change in grassland landscape was the second highest at a rate of $-9.14 \%$. The rate of change of unused land was the fastest from 1995 to 2005 with a dynamic degree of -8.51 , and the speed of change of grassland was the second with $91.42 \%$. The landscape change rate of reservoirs and ponds in the same period was the second, reaching $2.74 \%$. The calculated single land-use dynamic degree had the fastest change rate in building land, followed by grasslands, river channels, unused land, reservoirs, ponds, woodland, and cultivated land have the smallest changes from 1987 to 2015 . The change rate was the largest from 1987 to 1995, followed by $2005 \sim 2015$, and the smallest from 1995 to 2005 . Generally, the degree of land-use change is divided into four stages: $0 \sim 3 \%$ is a very slow change stage; 4 $\sim 12 \%$ is a slow change stage; $13 \sim 20 \%$ is a period of rapid change; $21 \sim 24 \%$ is a period of rapid change (Liu et al., 2005). It can be seen that the land-use change in the Yihe River Basin from 1987 to 2015 belongs to a very slow change stage.

\subsection{Changes in ESF and Supply-Demand Balance}

According to the four land-use maps of the Yihe River Basin in 1987, 1995, 2005 and 2015, combined with the ES supply potential (potential supply) matrix, the ESF (actual supply) matrix, and ES demand matrix (Tables 2, 3 and 4), the scores of potential supply, flow, and demand of ES are assigned to corresponding classes in the ArcGIS 10.1 platform. In the module of spatial analysis, the Formulas (3) and (4) were compiled into the program. In addition, the spatial display maps of the SR and SDR in the Yihe River Basin at different time scales were calculated based on different layers. Then, according to the area and proportion of the land type, the SR and SDR of the Yihe River Basin were calculated in the regional statistics module of GIS, and the index changes in different periods of the Basin were also compared.

\subsubsection{Changes in the Supply Rate of the Yihe River Basin}

SR represents the ratio of ES used by humans to the potential supply of ES. The minimum SR of the overall ES in the Yihe River Basin was 0.5000, and the maximum value was 0.9160 from 1987 to 2015 . The actual supply capacity of ES in the upper reaches of the Yihe River Basin is significantly lower than that in the middle and lower reaches in the past 30 years (Figure 4). The comparison of the SR of ES among multiple years presents that the total SR has relatively little variation in the Yihe River Basin from 1987 to 2015, declines from 0.7630 to 0.7520. The spatial explicit map shows that the ESF hotspots changed from 1987 to 2015 . It was mainly concentrated in the middle reaches of the river basin during 1987, most of them were located in Songxian city, followed by the south of Yanshi city. In 1995, the hotspots of the ESF were mainly concentrated in the upper reaches of the Yihe River Basin, located in the northern area of Luanchuan, Luoyang City. In 2005, the distribution of hotspot areas of the ESF in the Yihe River Basin was similar to these in 1987. Compared with previous years (i.e., 1987, 1995, and 2005) of the Yihe River Basin, the hotspot areas of ESF in 2015 have changed significantly in terms of area and spatial location, which was significantly reduced and northwardly shifted, mainly in Yanshi City.

The ES matrix is constructed on the basis of land cover. Different types of land cover provide different ES. Therefore, as the land cover of the Yihe River Basin changes in different years, its ecosystem service SR will also change. Although the ESF delivered to human communities in the Yihe River Basin accounts for a large proportion of the potential supply of ES, its ESF flow decreased slightly between 1987 and 2015. This is mainly due to the area of arable land and grassland has shrunk, while the area of construction land has increased sharply over the Yihe River Basin from 1987 to 2015.

\subsubsection{Changes in the Supply-Demand Ratio in the Yihe River Basin}

The SDR can reflect the balance between the actual supply of ecosystems and human demand in a given area. The spatial explicit map of the SDR in the Yihe River Basin can directly reveal the surplus or deficit of ES in different time-space scales. 

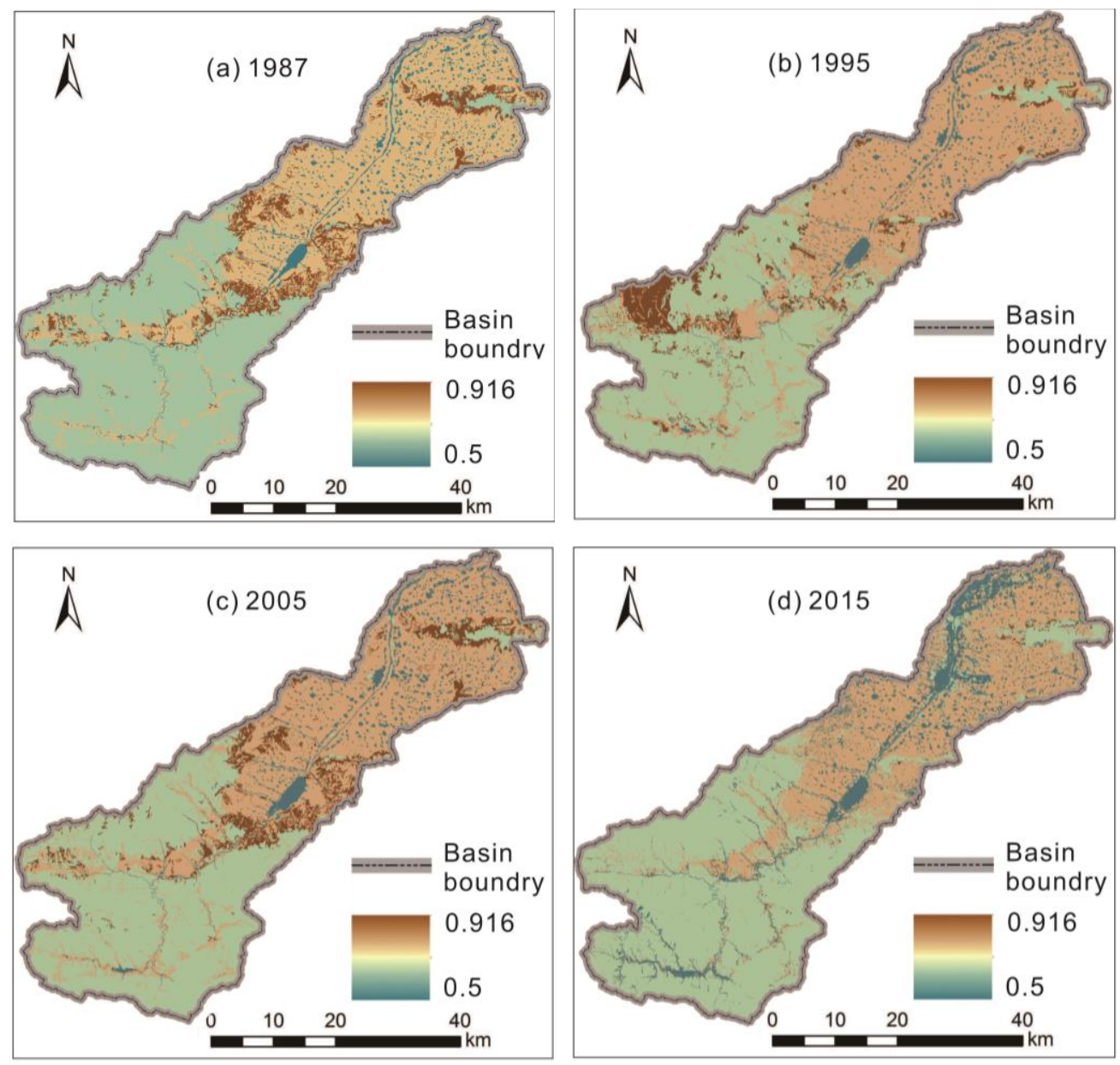

Figure 4. The spatial distribution of supply rate of ES in the Yihe River Basin from 1987 to 2015.

The supply and demand balance of the ecosystem in the Yihe River Basin has obvious spatial variation characteristics from 1987 to 2015. Most areas of the upstream are in ecological surplus, while most of the middle and lower areas are ecological deficit areas. The results show that the overall SDR index in the Yihe River Basin displays a significant descending trend from 1987 to 2015. Among them, the decline in the SDR index from 1987 to 2005 was relatively small, ranges from 0.8933 to 2005 . The supply-demand index of the Yihe River Basin decreased by 0.8676 in 2015, which was larger than 0.6519 (Figure 5). Although there are obvious deficits and surpluses in the upper, middle, and lower reaches of the Yihe River Basin, the Yihe River Basin is assumed to be a closed area. In the past 30 years, the overall ecosystem of the Yihe River Basin has been balanced, and the regional ecology is in a sustainable development stage.

The land-use of the Yihe River Basin is dominated by forests, followed by arable land, and the proportion of land occupied by building sites does not exceed 10\%. From 1987 to 2015, the supply rate and supply-demand ratio of overall ES were positive, and the supply of ES was generally in surplus of the basin. If the Yihe River basin is considered as a closed geo- graphical unit, the total services provided by the ecosystem can meet the human demand for ES within the basin as a whole. However, this does not mean that the supply of ES is in surplus in all areas of the basin, and local areas are still characterized by significant deficits. As can be seen in Figures 4 and 5, the supply rate, and supply-demand ratio vary spatially within the basin, and the landscape structure analysis shows that the upstream areas are predominantly covered by forest, and thus have the highest level of supply. The middle and lower streams of the basin are mainly composed of construction land and arable land, and their supply levels are low. The demand for services is high, so areas such as downstream construction land and arable land show a deficit. Therefore, ecosystem with high supply rates in the basin should be protected as a priority, and areas, where the supply of ES is in surplus should be used as the main areas for ecological compensation to guarantee the continuous output of their ES (Bai et al., 2017). Areas with high demand for ES should be ecologically restored, and ecologically protected, while the pathways and corridors for ES delivery between supply, and demand areas should be safeguarded usually to reduce the sinking landscape as much as possible (Liu et al., 2017a). 

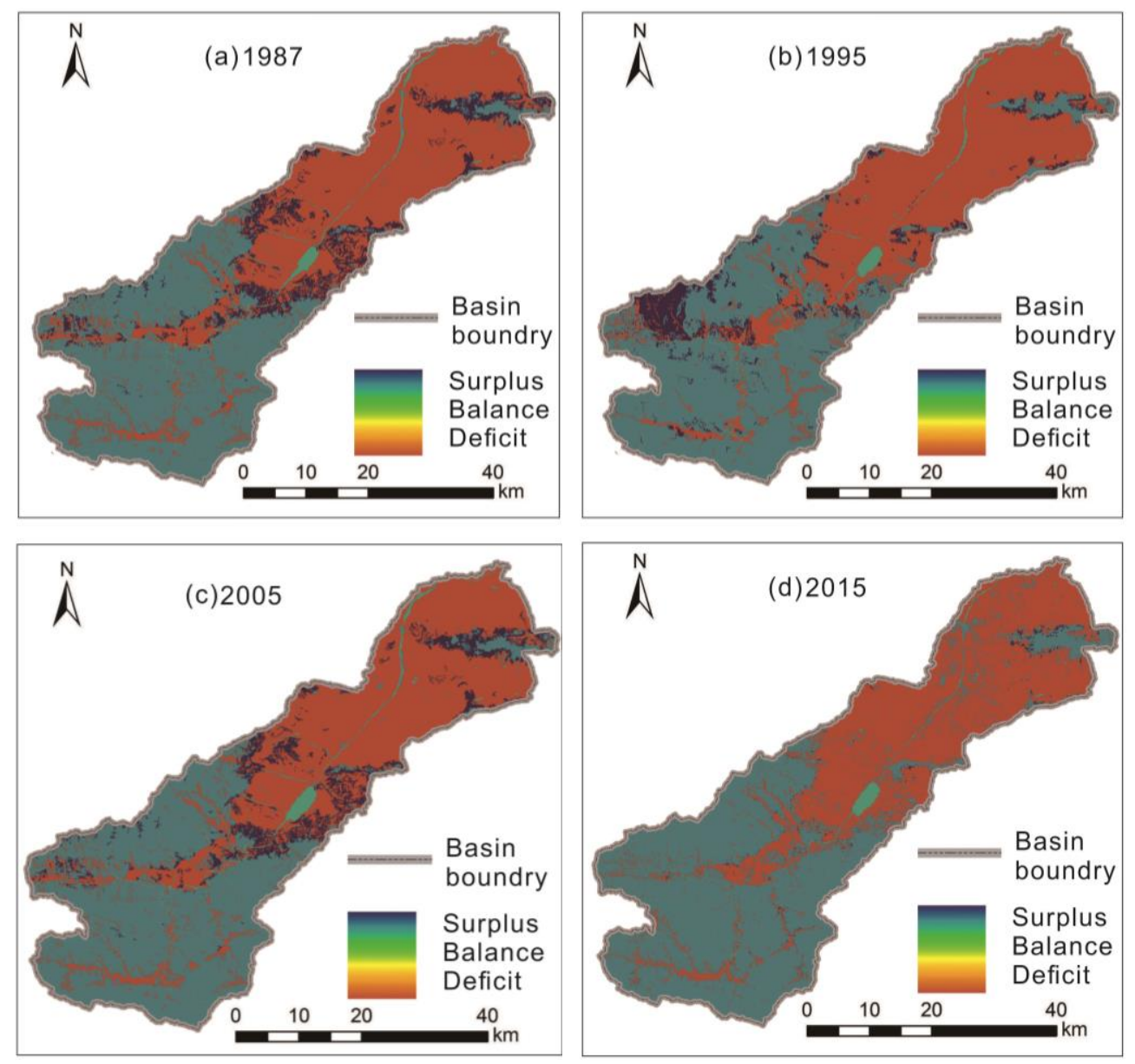

Figure 5. The spatial distribution of supply-demand ratio of ES in Yihe River Basin from 1987 to 2015.

\section{Conclusions and Discussion}

\subsection{Conclusions}

The landscape area and dynamic changes in Yihe River Basin were explored through ArcGIS, the constructed ES matrix based on expert experience, the two constructed indexes of SR and SDR through coupling the supply, and demand of ES. The two indexes were further used to analyze the ESF and their balance in the Yihe River Basin from 1987 to 2015. The results show that (1) The speed of single land-use change dynamics of construction land in the Yihe River Basin was the fastest in the past 30 years. The largest variation of comprehensive land-use change dynamics was occurred during $1987 \sim 1995$, while the smallest was in $1995 \sim 2005$. (2) The minimum and maximum values of the overall ecosystem services SR were 0.500 and 0.9160 over the Yihe River Basin in the past 30 years, respecttively. There is a noticeable spatial differentiation in the balance of supply and demand in the river basin. The upper reaches were in an ecological surplus area, while the middle and lower reaches were in the ecological deficit. (3) The actual ES delivered by the flows to humans account for a large proportion of potential ES in the Yihe River Basin. However, the ESF, and the balance of the ecosystem in the Yihe River Basin were de- creased during 1987 2015. Although the ecological deficit area in the basin was increased significantly, the Yihe River Basin was still in a sustainable state in 2015.

\subsection{Discussion}

The assessment of ESF, their coupled supply and demand combine theories, methods, techniques of modern landscape ecology, physical geography, environmental science, and computer science were used to analyze the landscape area of the Yihe River Basin and its dynamic changes. The changes of ESF, their potential supply of ES, human demand in the temporalspatial dimensions and the ecological balance of the Yihe River Basin were explored and assessed. The results of the study can guide ecological protection and environmental administration. They are important for maintaining the ecological sustainability of the watershed (Campagne and Roche, 2018). Therefore, to achieve ecological harmony in the Yihe River Basin, the forest in the upstream should be protected to improve the ecological environment of the mining area, adjust the industrial structure, and develop clean production. The construction of green corridors along the riverbanks should be carried out in the middle and lower reaches to ensure the safety of drinking water (Zhu et al., 2017). The downstream expansion of construction land 
and arable land has led to an unpromising ecological situation, so green agriculture should be developed to reduce agricultural surface pollution (Li et al., 2021).

This study focuses on assessing the potential supply of ES, ESF and human demand, using the ES matrix approach. The advantage is that it facilitates the relevant assessment of certain areas with missing data, while the disadvantage is that the scores determined based on expert experience and soil use/ground cover data are subjective and can lead to inaccurate results (Burkhard and Maes, 2017). Therefore, the ES matrix is an effective tool for exploring ESF and its supply-demand coupling relationship in data-deficient areas. The results attained through the ES matrix method also play an important role in regional ecological management (Campagne et al., 2017). At present, the ES matrix cannot be used as an accurate quantitative result to reflect the actual situation of ESF and its supply-demand relationship (Bai et al., 2017). If these relationships could be accurately evaluated in the future, accurate data, including regional socio-economic data, physical geographic data, spatial data and actual survey data, are needed to be obtained through innovative evaluation methods. This will be the focus of our followup study.

Acknowledgments. This research was supported by the National Key Research and Development Plan (2016YFA0601502), the Youth Project of Henan Natural Science Foundation (202300410029), the General Project of National Natural Science Foundation of China (41771202, 41371195), and the Youth Project of National Natural Science Foundation of China (31600374).

\section{References}

Bai, Y., Wang, M. and Li, H. (2017). Ecosystem services supply and demand: Theory and demand management application. Acta ecologica Sinica. 37(17), 5846-5852. https://doi.org/10.5846/stxb2016061 21124

Benjamin, B., Franziska, K., Stoyan, N. and Felix, M. (2012). Mapping supply, demand and budgets of ecosystem services. Ecological Indicators. 21, 17-29. https://doi.org/10.1016/j.ecolind.2011.06.019

Benjamin, B., Marion, K., Ying, H. and Felix, M. (2014). Ecosystem service potentials, flows and demands-concepts for spatial localisation, indication and quantification, Landscape Online. 34, 1-32. https://doi.org/10.3097/LO.201434

Burkhard, B. and Maes, J. (2017). Mapping Ecosystem Services. Pensoft Publishers, Sofia. 374 https://doi.org/10.3897/ab.e12837

Campagne, C.S. and Roche, P. (2018). May the matrix be with you! Guidelines for the application of expert-based matrix approach for ecosystem services assessment and mapping. One Ecosystem. 3. https://doi.org/10.3897/oneeco.3.e24134

Campagne, C.S., Roche, P., Gosselin, F., Tschanz, L. and Tatoni, T. (2017). Expert-based ecosystem services capacity matrices: Dealing with scoring variability. Ecological Indicators. 79, 63-72. https:// doi.org/10.1016/j.ecolind.2017.03.043

Daily, G.C. (1997). Nature Service: Societal Dependance on Natural Ecosystem. Washington DC: Island Press. ISBN: 1-55963-476-6

Deng, H.W. and Liao, Z.L. (2020). Review of drivers, supply and demand of ecosystem services. Environmental Science and Technology. 33(1), 75-78. https://doi.org/10.19824/j.cnki.cn32-1786/x.202 0.0014

Francesc, B., Ignacio, P., Grazia, Z., Pilar, V., Dagmar, H., Erik and G.B. (2016). Mapping ecosystem service capacity, flow and demand for landscape and urban planning: A case study in the Barcelona metropolitan region. Land use policy. 57, 405-417. https://doi.org/ 10.1016/j.landusepol.2016.06.006

Gao, W.W., Zeng, Y., Liu, Y., Yi, H.Y., Wu, B.F. and Ju, H.B. (2019). Forest dynamic monitoring by remote sensing from 2000 to 2015 in the water source area of the South-to-North Water Diversion Project. Scienia Sllvae Sinicae. 55(4), 97-107. https://doi.org/10.11707/j.10 01-7488.20190410

Gary, W. Luck., Richard, H., Paula, A.H., Claire, K., Pam, M.B., Rob, B., Terence, P.D., Francesco, d.B., Sandra, D., Christian, K.F., John, R.H., Daniel, H., Areti, K., Sandra, L., Mark, R., Michael, J.S., Leonard, S., Josef, S., Martin, T.S., Sybille, v.d.H., Marie, V. and Martin, Z. (2016). Quantifying the contribution of organisms to the provision of ecosystem services. BioScience. 59(3), 223-235. https://doi. org/10.1525/bio.2009.59.3.7

Lang, X.Z., Gao, P.L., Liu, X.W. and Chen, F. (2011). Study on the dynamic change of land use based on GIS in luozhong prefecture. $\mathrm{Hu}$ bei Agricultural Sciences. 50(3), 493-496. https://doi.org/10.14088 /j.cnki.issn0439-8114.2011.03.057

Li, D.H., Zhang, X.Y., Wang, Y., Zhang, X., Li, L. and Lu, Y. (2021). Evolution process of ecosystem services and the trade-off synergy in Xinan river basin. Acta ecologica sinica. 41(17), 1-10. https://doi. org/10.5846/stxb202010102575

Li, S.C. (2014). Geography Ecosystem Services. Science press. ISBN: 9787030405326

Liu, H.M., Fan, Y.L. and Ding, S.Y. (2016). Progress of ecosystem service flow. Chinese Journal of Applied Ecology. 27(7), 2161-21 71. https://doi.org/10.13287/j.1001-9332.201607.005 (in Chinese)

Liu, H.M., Liu, L.Y. and Ding, S.Y. (2017a). The impact of human activities on ecosystem service flow. Acta Ecologica Sinica. 37(10), 3232-3242. https://doi. org/10.5846/stxb201602250325

Liu, H.M., Liu, L.Y., Ren, J.Y., Bian, Z.Q. and Ding S.Y. (2017b). Progress of quantitative analysis of ecosystem service flow. Chinese Journal of Applied Ecology. 2017, 28(8), 2723-2730. https://doi. org/10.13287/j.1001-9332.201708.025 (in Chinese)

Liu, J.Y., Zhang, Z.X. and Zhuang, D.F. (2005). Study on Spatial and Temporal Information of Land Use Change in China in the 1990s. Beijing, Science Press. ISBN: 9787030147387

Liu, L.C., Liu, C.F., Wang, C. and Li, P.J. (2019a). Supply and demand matching of ecosystem services in loess hilly region: A case study of Lanzhou. Acta Geographica Sinica. 74(9), 1921-1937. https:// doi.org/10.11821/dlxb201909016 (in Chinese)

Liu, L.Y., Ding, S.Y., Ren, J.Y. and Bian, Z.Q. (2019b). Effects of landscape spatial heterogeneity on surface water quality service: A case study in Yihe River basin, Henan province. Geographical Research. 38(6), 1521-156. https://doi.org/10.11821/dlyj020180235

Liu, S.J., Guan, Y. and Zhang, Q. (2018). Influence of newly built river-crossing bridge on the lower Yihe River on riverbed erosion and siltation. Yellow River. 40(9), 34-36 https://doi.org/10.3969/j. issn.10001379.2018.09.008 (in Chinese)

Liu, Y.S., Gao. W.W., Hou, K. and Yang, Y. (2015). Analysis of ecologiacal environment change on watershehed. Resources and Environment in the Yangtze Basin. 24(3), 440-446 https://doi.org/10.118 70/cjlyzyyhj201503103 (in Chinese)

Ma, L., Liu, H., Peng, J. and Wu, J.S. (2017). A review of ecosystem services supply and demand. Acta Geographica Sinica. 72(7), 12771289. https://doi.org/10.11821/dlxb201707012 (in Chinese)

Millennium Ecosystem Assessment. (2005). Ecosystems and Human Well-Being: Synthesis. Washington DC: Island Press. ISBN: 1-559 63-402-2

Mo, L.C., Ma, R., Xie, Y. and Chen, J.C. (2021). Ecosystem service flows of wetlands blocking atmospheric PM2.5 in Beijing. Acta Ecologica Sinica. 41(14). 1-10. https://doi.org/10.5846/stxb202007 221925

Ren, J.Y., Liu, H.M., Ding, S.Y., Wang, M.N. and Bian Z.Q. (2017). Landscape pattern change and its driving mechanism in Yihe River 
basin, China. Chinese Journal of Applied Ecology. 28(8), 26112620. https://doi.org/10.13287/j.1001-9332.201708.023 (in Chinese)

Robert, C., Ralph, D.A., Rudolf. d.G., Stephen, F., Monica, G., Bruce, H., Karin, L., Shahid, N., Robert, V.O., Jose, P., Robert, G.R., Paul, S. and Marjan, V.D.B. (1997). The value of the world's ecosystem and natural capital. Nature. 23(2), 253-260. https://doi.org/10.1038/ $387253 \mathrm{a} 0$

Sala, O.E., Yahdjian, L., Havstad, K. and Aguiar, M.R. (2017). Rangeland ecosystem services: Nature's supply and humans' demand. Rangeland Systems. 467-489. https://doi.org/10.1007/978-3-319-46 709-214

Serna-Chavez, H.M., Schulp, C.J.E., Bodegom, P.M.V., Boutena, W., Verburgb, P.H. and Davidson, M.D. (2014). A quantitative framework for assessing spatial flows of ecosystem services. Ecological Indicators. 39, 24-33. http://dx.doi.org/10.1016/j.ecolind.2013.11.024

Shi, W., Lei, J., Ma, Y.L. and Yu, J.Y. (2019). Spatio-temporal drought characteristics in water source area of Middle Route Project of South-to-North Water Diversion based on SPEI. Yangtze River. 50 (7), 92-97. https://doi.org/10.16232/j.cnki.10014179.2019.07.015 (in Chinese)

Stoyan, N. and Benjamin, B. (2012). Flood regulating ecosystem services-Mapping supply and demand, in the Etropole municipality, Bulgaria. Ecological Indicators. 21, 67-79. https://doi.org/10.1016/j. ecolind.2011.06.022

Wang, J.L. and Zhou, W.Q. (2019). Ecosystem service flows: Recent progress and future perspectives. Acta Ecologica Sinica. 39(12), 4213-4222. https://doi.org/10.5846/stxb201807271605

Xie, G.D., Zeng, L., Lu, C.X., Chao, S.Y. and Xiao, Y. (2008). Supply consumption and valuation of ecosystem services in China. Resources Science. 30(1), 93-99. https://doi.org/10.3321/j.issn:1007-75 88.2008.01.014

Yin, N., Wang, S. and Liu, Y.X. (2021). Ecosystem service value assessment: Research progress and prospect. Chinese Journal of Ecology. 40(1), 233-244. https://doi.org/10.13292/j.1000-4890.2021 01.025 (in Chinese)

Zhang, X. and Lu, Q. (2020). Review of Ecosystem Service Flow in the Urban Scale. Environmental Protection Science. 46(6), 55-63. https://doi.10.16803/j.cnki.issn.1004-6216.2020.06.010 (in Chinese)

Zhu, H.Y. and Li, X.B. (2003). Discussion on the index mathod of regional land use change. Acta Geographica Sinica. 58(5), 643-650. https://doi.org/10.11821/xb200305001 (in Chinese)

Zhu, J., Li Y.M. and Yu Y.H. (2017). Study of construction and optimization of ecological security pattern of lake basin in plateau based on GIS - A case study of Xingyun Lake Basin. Resources and Environment in the Yangtze Basin. 26(8), 1237-1250. https://doi.org/10. 11870/cjlyzyyhj201708014 (in Chinese) 